\title{
LEISHMANICIDAL ACTIVITY OF Echinaster (Othilia) echinophorus CRUDE EXTRACT
}

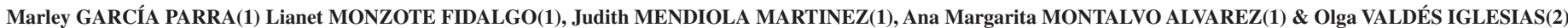

\begin{abstract}
SUMMARY
In this study, a methanolic extract from Echinaster (Othilia) echinophorus was evaluated for activity against Leishmania amazonensis. The extract showed activity against the promastigote and amastigote forms with $\mathrm{IC}_{50}$ values of 62.9 and $37.5 \mu \mathrm{g} . \mathrm{mL}^{-1}$ respectively. This extract showed a moderate toxicity on macrophages from BALB/c mice. A dose of $100 \mathrm{mg} / \mathrm{kg} / \mathrm{day}$ was effective when administered during 15 days by intraperitoneal route to BALB/c mice infected experimentally.
\end{abstract}

KEYWORDS: Leishmania amazonensis; Echinaster (Othilia) echinophorus; Antiprotozoal activity; Saponins.

\section{INTRODUCTION}

Leishmaniasis comprises a group of infectious diseases caused by organisms of the genus Leishmania and is a significant cause of morbidity and mortality in several countries ${ }^{34}$. The World Health Organization (WHO) estimates approximately 12 million affected individuals with an estimated annual incidence of 1.5 to 2 million. Approximately a 350 million people live at risk in 88 different countries ${ }^{10}$.

Due to the lack of a reliable human vaccine, in addition to the daunting control of parasite vectors and reservoirs, treatment relies exclusively on chemotherapy, with organic pentavalent antimonials as the first-line drugs ${ }^{17}$. Nevertheless, their efficacy is impaired by the growing incidence of parasite resistance and their frequent and severe side effects $^{19}$. Alternative treatments, based on amphotericin B, paramomycin, allopurinol, and more recently miltefosine, are also available ${ }^{17}$, although most of these treatments give rise to secondary effects ${ }^{7}$. Thus, there is a pressing need for new leishmanicidal drugs.

The marine organisms are a rich source of varied natural products with unique properties. Marine natural products chemistry has undergone an explosive growth during the past three decades ${ }^{11}$. Echinaster genus includes marine invertebrates that are usually associated with hard substrates; they generally live in shallow water, beneath coral rubble and rock and have been found clinging to mangrove roots ${ }^{18}$. In the literature, no pharmacological reports of antileishmanial activity for Echinaster species were found, although antimalarial activity has been described ${ }^{25}$. In this work, the in vitro and in vivo antileishmanial activity of an alcoholic extract of Echinaster echinophorus against Leishmania amazonensis is evaluated.

\section{MATERIAL AND METHODS}

1. Methanolic extract from E. echinophorus: Nine specimens of marine invertebrate E. echinophorus Lamarck 1816 (Echinodermata fam.) were collected by snorkelling and scuba diving at Puerto Esperanza $\left(22^{\circ} 50^{\circ} \mathrm{N} ; 83^{\circ} 46^{\circ} \mathrm{W}\right)$, on the North coast of Pinar del Rio, Cuba, in February 2006. The sample was classified by Aida Hernández Sarduy, PhD and Macario Ezquivel, both specialists of The Institute of Oceanology and it was deposited at the Voucher Collection of National Aquarium of Cuba [IdO 10.1.0009].

The crude extract was prepared by homogenizing of the organisms (144.5 g wet weigh) with methanol pa. (Riedel-deHaën No 32213) at 70\% using a Waring-Blendor homogenizer. The suspension was macerated at 4 ${ }^{\circ} \mathrm{C}$ during 72 hours with mechanical agitation, followed by centrifugation at $10,000 \mathrm{x}$. The supernatant was concentrated using a vacuum rotary evaporator, lyophilized and stored at $-20{ }^{\circ} \mathrm{C}$. The lyophilized extract of E. echinophorus ( $0.5 \mathrm{~g}$ equal to $0.35 \%$ of yield) was dissolved in distilled water and partitioned with trichloromethane pa. (Merck No 2445) to get two fractions of different polarity. The qualitative phytochemical analyses were run for both fractions to identify the various types of secondary metabolites present, including saponins, flavonoids, phenols and tannins, glycosides, alkaloids, triterpenoids and steroids, amino acid and quinones ${ }^{8,23}$.

2. Spectroscopy (UV- visible): The UV-visible spectrum of the crude extract was obtained in a Shimadzu spectrophotometer UV-1201 (Japan). The determination of the sample was made with a dilution of $1 \mathrm{mg} \cdot \mathrm{mL}^{-1}$ against methanol and the maximum of the absorbance in the range of 200 to $800 \mathrm{~nm}$, in the quartz cell of $1 \mathrm{~cm}$ of light pass.

(1) Departmento de Parasitología, Instituto de Medicina Tropical "Pedro Kourí". Ciudad de la Habana, Cuba.

(2) Centro de Bioproductos Marinos, Loma st. \& 39. Ciudad de la Habana, Cuba.

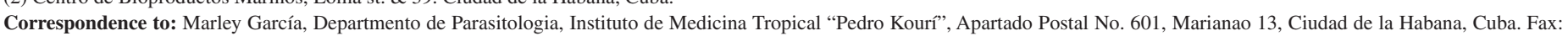
(537) 2046051. E-mail: marley@ipk.sld.cu 


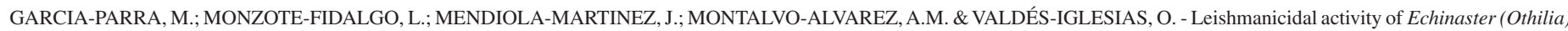
echinophorus crude extract. Rev. Inst. Med. Trop. Sao Paulo, 52(2):89-93, 2010

For their pharmacological evaluation, the extract and fractions were diluted in dimethyl sulphoxide (DMSO, BDH, Poole, England), at a concentration of $20 \mathrm{mg} \cdot \mathrm{mL}^{-1}$, and stored at $4{ }^{\circ} \mathrm{C}$.

3. Reference drug: Amphotericin B (AmB; Quimefa, Havana City, Cuba) was used as the reference drug, at a concentration of $2 \mathrm{mg} \cdot \mathrm{mL}^{-1}$ (stock solution). Dilutions of the drug were prepared using distilled water.

4. Parasites: The MHOM/77BR/LTB0016 strain of L. amazonensis was kindly provided by the Department of Immunology, Oswaldo Cruz Foundation (FIOCRUZ) Brazil. Parasites were routinely isolated from mouse lesions and maintained as promastigotes at $26^{\circ} \mathrm{C}$ in Schneider's medium (SIGMA, St. Louis, MO, USA) containing $10 \%$ heat-inactivated fetal bovine serum (HFBS) (SIGMA, St. Louis, MO, USA), $100 \mu \mathrm{g} \cdot \mathrm{mL}^{-1}$ streptomycin, and $100 \mathrm{U} . \mathrm{mL}^{-1}$ penicillin. The parasites were used no later than ten passages in culture medium.

5. Laboratory animals: Female BALB/c mice, with a body weight of approximately 20-22 g, were obtained from the National Centre of Laboratory Animals Production (CENPALAB). The maintenance and care of mice was carried out following the guidelines from the Ethics Committee for the Human Use of Laboratory Animals.

\section{Biological evaluations}

6.1. Antipromastigote activity: Five concentrations of the crude extract of E. echinophorus were assayed. Exponentially growing cells ( $10^{5}$ promastigotes. $\mathrm{mL}^{-1}$ in $198 \mu \mathrm{L}$ of Schneider's completed medium) were distributed in 96-well plates. Two microliters of extract dissolved in DMSO was added to well plates at a final concentration between 6.25 and $200 \mu \mathrm{g} \cdot \mathrm{mL}^{-1}$, and incubated at $26^{\circ} \mathrm{C}$. After three days of exposure, the parasites were incubated for three hours with p-nitrophenyl phosphate (20 mg. mL ${ }^{-1}$ ) dissolved in 1 mol.L $\mathrm{L}^{-1}$ sodium acetate buffer (BDH, Poole, England), pH 5.5, with 1\% Triton X-100 (BDH, Poole, England) at 37 ${ }^{\circ} \mathrm{C}$. The absorbance was determined in an EMS Reader MF Version 2.40 , at a wavelength of $405 \mathrm{~nm}^{3}$. The $50 \%$ of the inhibitory concentration $\left(\mathrm{IC}_{50}\right)$ was obtained from dose-response curves fit to data by means of the lineal equation ${ }^{2}$. For testing AmB the same methodologies were followed with final concentration of $\mathrm{AmB}$ between 0.006 and $0.1 \mu \mathrm{g} . \mathrm{mL}^{-1}$. The control parasites were treated with $2 \mu \mathrm{L}$ of DMSO (vehicle). This test was performed in triplicate.

6.2. Antiamastigote activity: Resident macrophages were collected from peritoneal cavities of BALB/c mice in ice-cold RPMI 1640 medium (SIGMA, St. Louis, Mo, USA) supplemented with antibiotics, plated at $10^{6} / \mathrm{mL}$ in $24-$ Well Lab-Tek (Costar, USA) and led to adhere for two hours at $37^{\circ} \mathrm{C}$ in $5 \% \mathrm{CO}_{2}$. Non-adherent cells were removed by washing with PBS, and then, stationary-phase L. amazonensis promastigotes were added at a 4:1 parasite/macrophage ratio. The cultures were incubated for another four hours and the cell monolayers were washed three times with pre-warmed PBS to remove free parasites. Then, $980 \mu \mathrm{L}$ of the RPMI complete medium and $20 \mu \mathrm{L}$ of the extract, at final concentrations between 12.5 to $100 \mu \mathrm{g} \cdot \mathrm{mL}^{-1}$, were added for a further 48 hours ${ }^{23}$. The cultures were then fixed with absolute methanol, stained with Giemsa, and examined under light microscopy. The number of intracellular amastigotes was determined by counting the amastigotes residents on 100 macrophage per each sample, and the results were expressed as percent of reduction of the infection rate (\% IR) in comparison to that of the controls [ $($ IRTC $=$ infection rate of the treated culture; IRUC $=$ infection rate of the untreated culture)]. The infection rates were obtained by multiplying the percentage of infected macrophages by the number of amastigotes per infected macrophages ${ }^{9}$. The $\mathrm{IC}_{50}$ value was calculated by linear regression analysis. Each experiment was performed twice on different occasions.

6.3. Cytotoxicity assay: The cytotoxicity of the extract was determined on peritoneal macrophages from BALB/c mice. Macrophages were collected and seeded at $10^{5}$ cells. $\mathrm{mL}^{-1}$. After two hours of incubation at $37{ }^{\circ} \mathrm{C}$ in $5 \% \mathrm{CO}_{2}$, non-adherent cells were removed with $\mathrm{PBS}$ and $2 \mu \mathrm{L}$ of dilutions of the extracts was added to $198 \mu \mathrm{L}$ of medium at $10 \%$ of HFBS and antibiotics. The macrophages were treated with five concentrations of the extract, ranging from 12.5 to $200 \mu \mathrm{g} \cdot \mathrm{mL}^{-1}$ for 48 hours. Cultures treated with $2 \mu \mathrm{L}$ of DMSO were included as controls. The cytotoxicity was determined using the colorimetric assay with 3-[4,5-dimethylthiazol-2-yl]-2,5-diphenyltetrazolium bromide (MTT) (SIGMA, St. Louis, MO, USA). MTT solutions were prepared at 5 mg.mL ${ }^{-1}$ in PBS, filtered and sterilized at the time of use and $15 \mu \mathrm{L}$ was added to each well. After incubation for an additional four hours the formazan crystals were dissolved by the addition of $100 \mu \mathrm{L}$ of DMSO. The optical density was determined using an EMS Reader MF Version 2.4-0, at a wavelength of $560 \mathrm{~nm}^{30}$. This test was performed in triplicate.

The $\mathrm{IC}_{50}$ was obtained from dose-response curves fitted to data by means of linear equation. The selectivity index $(\mathrm{SI})$ ratio $\left(=\mathrm{IC}_{50}\right.$ for macrophage/ $\mathrm{IC}_{50}$ for amastigotes) was used to compare the toxicity of the extract for murine macrophage and the activity against intracellular amastigotes of Leishmania ${ }^{32}$.

7. In vivo studies: The activity of the crude extract of E. echinophorus was evaluated on mice experimentally infected with $L$. amazonensis. Groups of five BALB/c mice were randomly assigned to receive the extract dissolved in physiological saline solution. The treatment consisted of one daily intraperitoneal injection, at doses of $100 \mathrm{mg} \cdot \mathrm{kg}^{-1}$ for two weeks. Mice were observed daily, the body weight of each mouse was measured each week from the beginning of the treatment up to six weeks post-infection. On day 0 , mice were infected with $0.2 \mathrm{~mL}$ of parasite suspension containing $10^{7}$ promastigotes of L. amazonensis, collected in the late logarithmic phase, by subcutaneous route in the right footpads. Disease progression was monitored by weekly assessment of the lesion diameters using an automatic calliper in vertical position. Average lesion size was calculated as the differences obtained between infected and uninfected footpads. At four and six weeks post-infection, three animals were sacrificed by cervical dislocation and the parasite burden was determined using the culture microtitre method ${ }^{3}$. A sample of the lesion was excised, weighed and homogenized in Schneider's medium with $10 \%$ HFBS and antibiotics. Under sterile conditions 4-fold serial dilutions were prepared in wells of 96-well microtitre plates containing $225 \mu \mathrm{L}$ of culture medium and incubated at $26^{\circ} \mathrm{C}$. Three replicates were done of each piece. The presence or absence of mobile promastigotes in each well was verified after seven days of incubation. The parasite burden was calculated as follows: parasite burden $=$ (geometric mean of reciprocal titres from each duplicated/weight of homogenized cross section) $\mathrm{x} 400$. Data on lesion progression and parasite burden were analyzed for statistical significance by the analysis of variance test, following of a Post Hoc Test (LDS test or planned comparison) using the Statistical for Windows program, Version 4.5, StatSoft, Inc. 1993. 


\section{RESULTS}

Ten qualitative chemical reactions were performed to identify the secondary metabolite components of the polar and non-polar fractions of the extract. We observed the presence of three groups of compounds in the aqueous fraction (amino acids, phenols and tannins and saponin) and only one type of component in the non polar phase (quinones). The results of spectral analysis of the methanolic extract of E. echinophorus showed three maxima corresponding with the following wavelengths: $301 \mathrm{~nm}(2,028) ; 362 \mathrm{~nm}(1,229) ; 466 \mathrm{~nm}(0,533)$.

Table 1 shows the in vitro activity of the extract of E. echinophorus against $L$. amazonensis. The activity against intracellular amastigotes was two-fold higher than against the promastigote form with a SI of 9.

Treatment of mice with the extract did not result in animal death and the weight loss was less than $10 \%$ (Table 2).

\section{Table 1}

In vitro activity of the extract of E. echinophorus and Amphotericin B against L. amazonensis

\begin{tabular}{lcccc}
\hline \multirow{2}{*}{ Tested drugs } & \multicolumn{3}{c}{$\mathrm{IC}_{50}\left(\mu \mathrm{g} \cdot \mathrm{mL}^{-1}\right)^{\mathrm{a}} \pm \mathrm{SD}^{\mathrm{b}}$} & \multirow{2}{*}{$\mathrm{SI}^{\mathrm{c}}$} \\
\cline { 2 - 4 } & promastigote & amastigote & macrophages & \\
\hline Extract of & $62.9 \pm 1.3$ & $37.5 \pm 4.7$ & $348.6 \pm 2.4$ & 9 \\
E. echinophorus & & & & \\
Amphotericin B & $0.03 \pm 0.003$ & $<1$ & $5.8 \pm 0.5$ & 193 \\
\hline
\end{tabular}

a: $\mathrm{IC}_{50}$ : Concentration of drug that caused $50 \%$ of mortality. To assay promastigote, a colorimetric method was used due to phosphatase activity. To assay amastigotes a direct counting of cultures stained by Giemsa was carried out. To assay macrophage a colorimetric method was performed with a tetrazolium salt (MTT). The control showed $5.2 \pm 0.6$ average of amastigote per macrophage and $96 \pm 4 \%$ of macrophage infected; ${ }^{\mathrm{b}}$ : SD: standard deviation; ${ }^{\mathrm{c}}$ : SI: $\mathrm{IC}_{50}$ for macrophages/ $\mathrm{IC}_{50}$ for promastigotes.

Table 2

Mortality and corporal weight variation of BALB/c mice after 15 days of treatment with methanolic extract of E. echinophorus at $100 \mathrm{mg} \cdot \mathrm{kg}^{-1}$ by intraperitoneal route

\begin{tabular}{lccccc}
\hline Groups & Mortality & \multicolumn{4}{c}{ Gain or loss of weight in mice (g) } \\
\cline { 3 - 6 } & $(\%)$ & Week 1 & Week 2 & Week 3 & Week 4 \\
\hline E. echinophorus & 0 & 1.0 & 6.1 & 5.4 & 13.9 \\
Vehicle & 0 & 4.0 & 4.0 & 7.5 & 15.0 \\
Untreated & 0 & 4.3 & 7.5 & 11.7 & 15.7 \\
\hline
\end{tabular}

The effect of treatment on infected BALB/c mice with extract, vehicle or AmB by intraperitoneal route is presented in Fig. 1. A significant reduction $(p<0.05)$ in the size of the lesions from animals treated with the extract was observed at four weeks post-infection, compared to the other groups. After treatment, the lesions began to grow, although there was still a significant difference at week six of post-infection $(p<0.05)$.

The mice treated with AmB had enlarging lesions, and the size of the lesions was statistically not different $(p>0.05)$ from the untreated group. Intraperitoneal treatment with vehicle induced no effect $(p>$ $0.05)$.

The activity of the extract against Leishmania infections was verified by determination of the parasite burden in the lesion. We observed that the alcoholic extract produced a significant suppression $(p<0.05)$ of the number of parasites in the infected footpads, compared to the other test groups (Fig. 2).

\section{DISCUSSION}

Active compounds from terrestrial and marine organisms have

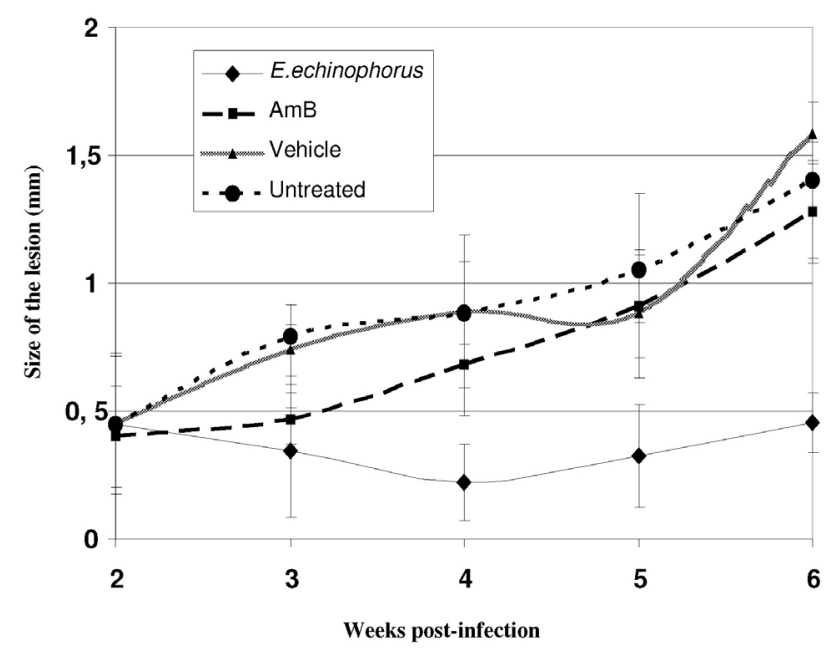

Fig. 1 - Effects of treatment with the methanolic extract of E. echinophorus (100 mg.kg ${ }^{-1}$ ) and Amphotericin B ( $\left.1 \mathrm{mg} . \mathrm{kg}^{-1}\right)$ administered daily for 15 days by intraperitoneal route, during the course of infection of BALB/c mice with L amazonensis. Each point represents the mean \pm the standard deviation of the mean difference in lesion size between infected and uninfected footpads of twelve mice.

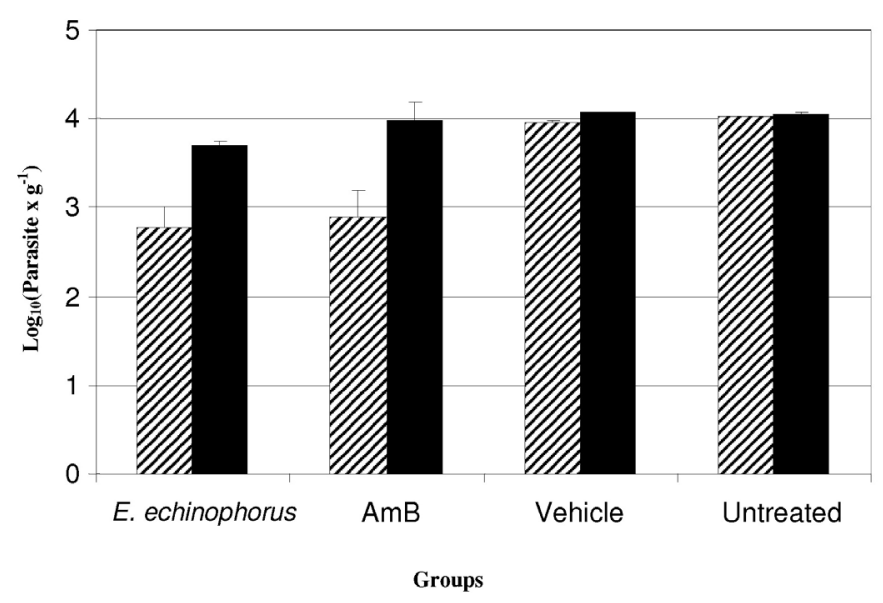

Fig. 2 - Parasite burden of mice infected with L. amazonensis and treated with the methanolic extract of E. echinophorus (100 mg. $\left.\mathrm{kg}^{-1}\right)$, Amphotericin B $\left(1 \mathrm{mg} \cdot \mathrm{kg}^{-1}\right)$ and vehicle $(0.1 \mathrm{~mL})$ administered daily for 15 days by intraperitoneal routes. An untreated group was included as positive control. The determinations of parasite burden were carried out on the $15^{\text {th }}$ and $30^{\text {th }}$ day of post-infection. The values represent the mean \pm the standard deviation of the mean for three mice. 


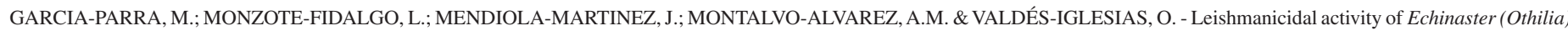
echinophorus crude extract. Rev. Inst. Med. Trop. Sao Paulo, 52(2):89-93, 2010.

extensive use in the treatment of several diseases and serve as compounds of interest both in their natural form and as templates for synthetic modification. Over 20 new drugs derived from natural sources have been launched in the market during 2000-2005. These new drugs have been approved for the treatment of cancer, neurological diseases, infectious diseases, cardiovascular and metabolic diseases ${ }^{5}$. In this sense, previous compounds isolated from marine organism have been reported with antileishmanial activity; these include a glycoprotein isolated from Pachymatisma johnstoni ${ }^{24}$, a lectin from Cliona varians ${ }^{27}$ and three sulfated meroterpenoids from Callyspongia sp. ${ }^{16}$.

Previous studies have reported the isolation of "asterosaponins" from Echinaster braziliensis ${ }^{20}$; similarly, the phytochemical analysis of the extract of E. echinophorus revealed the presence of amino acids, phenols and saponins in the aqueous phase, and of quinones in the organic phase. Both saponins ${ }^{12,14,15,24}$ and quinones ${ }^{31}$ have shown activity against Leishmania parasites.

The extract of E. echinophorus showed activity against both promastigotes and amastigotes forms of the parasite. In parallel evaluation of the cytotoxicity of the extract against host cells, the extract showed a selectivity index (SI) of nine; this is particularly relevant since it has been reported that products with an SI value greater than one are considered to be more selective in their activity against parasites, while those with an SI value lower than one are considered more selective in their activity against host cells ${ }^{6,32}$. The SI shown by the extract of E. echinophorus indicated that the action of the extract is specific for the Leishmania parasites and that it is not toxic for mouse peritoneal macrophages. $\mathrm{The}_{\mathrm{IC}}$ and $\mathrm{SI}$ values shown by the extract of $E$. equinophorus justify its evaluation against leishmaniasis in an animal model of infection, with the objective of validating the extract as a promissory source of antileishmanial products.

Even though experimental cutaneous leishmaniasis caused by $L$. amazonensis has been used in several studies evaluating new natural ${ }^{4,9,13,28}$ and synthetic antileishmanial products ${ }^{4,26}$, treatment of animals infected with $L$. amazonensis with the extract of E. echinophorus reduced the size of the lesions and the parasite load in the infected footpads without causing death, loss of weight or any observable signs of toxicity. However, the cure was not complete; possibly because L. amazonensis-infected $\mathrm{BALB} / \mathrm{c}$ mice are not adequate for testing the effectiveness of products against leishmaniasis, because a high multiplication rate of parasites at the site of the lesion occurs ${ }^{14}$. In addition, BALB/c mice are highly susceptible to Leishmania parasites, showing a progressive infection that may promote metastasis ${ }^{1}$, and are more susceptible to L. amazonensis than other inbred mice ${ }^{21}$.

It is interesting to point out that in our study, AmB did not prevent the progression of the cutaneous disease in infected animals even though the susceptibility of the strain of L. amazonensis to AmB was confirmed (Table 2) and the dose of the drug administered by parenteral route was similar to that recommended in the literature. These results, i.e. the low effectivity of AmB in animals experimentally infected with L. amazonensis, are in agreement with those reported in the literature ${ }^{1}$.

In conclusion, we believe that the extract of E. echinophorus represents a potential source on new antileishmanial natural products because of its activity against the parasite causing cutaneous leishmaniasis and its low toxicity.

\section{RESUMO}

\section{Atividade leishmanicida do extrato de Echinaster (Othilia) echinophorus}

Neste estudo descreve-se o efeito de um extrato metanólico de Echinaster echinophorus spp. no parasita Leishmania amazonensis. Em testes com as formas promastigotas e amastigotas, o $\mathrm{IC}_{50}$ do extrato foi 62,9 e $37,5 \mu \mathrm{g} \cdot \mathrm{mL}^{-1}$, respectivamente. $\mathrm{O}$ extrato também tem toxicidade moderada em macrófagos de camundongos BALB/c. O tratamento de camundongos BALB/c infectados com $L$. amazonensis com doses diárias de $100 \mathrm{mg} / \mathrm{kg} / \mathrm{dia}$ via intraperitoneal durante 15 dias mostrou-se relativamente efetivo no controle da infecção. Esta investigação confirma a importância de produtos naturais como fonte para a descoberta de fármacos com funções anti-Leishmania.

\section{ACKNOWLEDGEMENTS}

To Dra Aida Hernandez Zanuy from Institute for Marine Science, Cuba, for donating and the identification of samples of E. echinophorus and Dr. Paul Cos from University of Antwerp, Belgium, for their comments and revision of this manuscript.

\section{REFERENCES}

1. Al-Abdely HM, Graybill JR, Loebenberg D, Melby PC. Efficacy of the triazole SCH 56592 against Leihmania amazonensis and Leishmania donovani in experimental murine cutaneous and visceral leishmaniasis. Antimicrob Agents Chemother. 1999;43:2910-4.

2. Bodley AL, McGarry MW, Shapiro TA. Drug cytotoxicity assay for African trypanosomes and Leishmania species. J Infect Dis. 1995;172:1157-9.

3. Buffet PA, Sulahian A, Garin YJF, Nassar N, Derouin F. Culture microtitration: a sensitive method for quantifying Leishmania infantum in tissues of infected mice. Antimicrob Agents Chemother. 1995;39:2167-8.

4. Chan-Bacab MJ, Balanza E, Deharo E, Muñoz V, García RD, Peña-Rodríguez LM. Variation of leishmanicidal activity in tour populations of Urechites andrieuxii. J Ethnopharmacol. 2003;86: 243-7.

5. Chin YW, Balunas MJ, Chai HB, Kinghorn D. Drug discovery from natural sources. AAPS J. 2006;8:E239-53.

6. Cos P, Vlietinck AJ, Berghe DV, Maes L. Anti-infective potential natural products: how to develop a stronger in vitro "proof-of-concept". J Ethnopharmacol. 2006;106:290302 .

7. Croft SL, Yardley V. Chemotherapy of leishmaniasis. Curr Pharm Des. 2002;8: 319-42.

8. Cuéllar A. Métodos de extracción. In: Miranda M, Cuéllar A. Farmacognosia y productos naturals. La Habana; 2001. p. 25-7.

9. Delorenzi JC, Attias M, Gattass CR, Andrade M, Rezende C, da Cunha Pinto A. Antileishmanial activity of an indole alkaloid from Peschiera australis. Antimicrob Agents Chemoter. 2001;45:1349-54.

10. Desjeux P. Leishmaniasis: current situation and new perspectives. Comp Immunol Microbiol Infect Dis. 2004;27:305-18.

11. Dunlap WC, Battershill CN, Liptrot CH, Cobb RE, Bourne DG, Jaspar M, et al. Biomedicinals from the phytosymbionts of marine invertebrates: a molecular approach. Methods. 2007;42:358-76. 
12. Dutta A, Ghoshal A, Mandal D, Mondal NB, Banerjee S, Sahu NP, et al. Racemoside A, an anti-leishmanial, water-soluble, natural steroidal saponin, induces programmed cell death in Leishmania donovani. J Med Microbiol. 2007;56:1196-204.

13. Fournet A, Ferreira ME, Rojas de Arias A, Torres de Ortiz S, Fuentes S, Nakayama $\mathrm{H}$, et al. In vivo efficacy of oral and intralesional administration of 2-substituted quinolines in experimental treatment of New World cutaneous leishmaniasis caused by Leishmania amazonensis. Antimicrob Agents Chemother. 1996;40:2447-51.

14. Fuchino H, Sekita S, Mori K, Kawahara N, Satake M, Kiuchi F. A new leishmanicidal saponin from Brunfelsia grandiflora. Chem Pharm Bull (Tokyo). 2008;56:93-6.

15. Germonprez N, Maes L, Van Puyvelde L, Van Tri M, Tuan DA, De Kimpe N. In vitro and in vivo anti-leishmanial activity of triterpenoid saponins isolated from Maesa balansae and some chemical derivatives. J Med Chem. 2005:48:32-7.

16. Gray CA, de Lira SP, Silva M, Pimenta EF, Thiemann OH, Oliva G, et al. Sulfated meroterpenoids from the Brazilian sponge Callyspongia sp. are inhibitors of the antileishmaniasis target adenosine phosphoribosyl transferase. J Org Chem. 2006;71:8685-90.

17. Guerin PJ, Olliaro P, Sundar S, Boelaert M, Croft SL, Desjeux P, et al. Visceral leishmaniasis: current status of control, diagnosis, and treatment, and a proposed research and development agenda. Lancet Infect Dis. 2002;2:494-501.

18. Handler G, Miller JE, Pawson DL, Kier PM. Sea stars, Sea Urchins, and Allies. Smithsonian Institution; 1995. p. 84-5

19. Herwaldt BL. Leishmaniasis. Lancet. 1999;354:1191-9.

20. Iorizzi M, de Riccardis F, Minale L, Riccio R. Starfish saponins, 52. Chemical constituents from the starfish Echinaster brasiliensis. J Nat Prod. 1993;56:2149-62.

21. Ji J, Sun J, Qi H, Soong L. Analysis of T-helper cell responses during infection with Leishmania amazonensis. Am J Trop Med. 2002;66:338-45.

22. Le Pape P, Zidane M, Abdala H, Moré MT. A glycoprotein isolated from the sponge, Pachymatisma johnstonii, has antileishmanial activity. Cell Biol Int. 2000;24:51-6.

23. Lock O. Investigación Fitoquímica. $2^{\text {a }}$ ed. Perú: Pontificia Universidad Católica del Perú Fondo editorial; 1994.

24. Mandal D, Panda N, Kumar S, Banerjee S, Mandal NB, Sahu NP. A triterpenoid saponin possessing antileishmanial activity from the leaves of Careya arborea. Phytochemistry. 2006;67:183-90.
25. Mendiola J, Hernández H, Sariego I, Rojas L, Robles R, Otero A, et al. Antimalaria activity from three ascidians: an exploration of different marine invertebrate phyla. Trans R Soc Trop Med Hyg. 2006;100:909-16.

26. Monteiro MC, Marques FCS, Blazius RD, Santos da Silva O, Cunha FQ, Bento $\mathrm{DB}$, et al. $\mathrm{N}$-acetyl-L-cysteine reduces the parasitism of BALB/c mice infected with Leishmania amazonensis. Parasitol Res. 2008;102:801-3.

27. Moura RM, Queiroz AF, Fook JM, Dias AS, Monteiro NK, Ribeiro JK, et al. CvL, a lectin from the marine sponge Cliona varians: isolation, characterization and its effects on pathogenic bacteria and Leishmania promastigotes. Comp Biochem Physiol. A Mol Integr Physiol. 2006;145:517-23.

28. Plock A, Sokolowska WK, Presber W. Application of flow citometry and microscopica methods to characterize the effect to herbal drugs on Leishmania spp. Exp Parasitol. 2001;97:141-53

29. Rodríguez N, Bailey BN, Martin MB, Oldfield E, Urbina J, Docampo R. Radical cure of experimental cutaneous leishmaniasis by the bisphosphanate pamdronate. J Infect Dis. 2002; 186:138-40.

30. Sladowski D, Steer SJ, Clothier RH, Balls M. An improved MTT assay. J Immunol Methods. 1993;157:203-7.

31. Teixeira MJ, de Almeida YM, Viana JR, Holanda Filha JG, Rodrigues TP, Prata Jr $\mathrm{JR}$, et al. In vitro and in vivo leishmanicidal activity of 2-hydroxy-3-(3-methyl-2 butenyl)-1,4-naphthoquinone (lapachol). Phytother Res. 2001;15:44-8.

32. Tiuman TS, Ueda-Nakamura T, Garcia Cortez DA, Dias Filho BP, Morgado-Díaz JA de Souza W, et al. Antileishmanial activity of parthenolide, a sesquiterpene lactone isolated from Tanacetum parthenium. Antimicrob Agents Chemother. 2005;49:176-82.

33. Torres-Santos EC, Moreira DL, Kaplan MAC, Meirelles MN, Rossi-Bergmann B Selective effect of 2',6'-dihydroxy-4'-methoxyclacone isolated from Piper aduncum on Leishmania amazonensis. Antimicrob Agents Chemother. 1999;43:1234-41.

34. World Health Organization. Leishmaniasis: the disease and its impact. [Online.] 2001. http://www.who.int/emc/diseases/leish/leisdis1.html. Accessed 14 April 2003

Received: 6 November 2008

Accepted: 12 January 2009 